\title{
Evaluation of energy effects of the heat distribution network modernization
}

\author{
Tomasz Kujawa ${ }^{1}$, and Aleksander Stachel ${ }^{1, *}$ \\ ${ }^{1}$ West-Pomeranian University of Technology, Szczecin, Department of Heat Engineering, al. Piastów 17, PL-70-310 Szczecin, Poland
}

\begin{abstract}
The work concerns the estimation of energy effects of modernization of a part of an existing heat distribution main, which is part of a system that supplies heat for heating and domestic hot water preparation. The energy effect was defined as the difference between heat losses in the installation previously operated, developed in the technology of traditionally insulated pipes placed in dedicated underground channels and newly built installations made of pre-insulated pipes located directly in the ground. In the paper, in a synthetic way, the method of calculation is presented, as well as the accompanying assumptions. Two basic approaches to determine the heat losses are discussed. The first one was based on detailed calculations based on real operational data, whereas the second one used the indicative method recommended by the National Fund for Environmental Protection and Water Management (NFOŚiGW). The results obtained on this basis show that the modernization of the installation returns measurable energy effects in the form of reduced heat losses, which translates into the efficiency of its operation and operation of the source. At the same time, they show that the size of obtained energy effect depends on the applied methodology of calculations.
\end{abstract}

\section{Introduction}

One of the expectations related to the modernization of heating systems is the estimation of energy effects (sometimes also the ecological ones) resulting from the applied technical solutions. The element of the assessment is usually the reduction of energy consumption in the installation after modernization. In the case of heating networks, this is associated with determination of the amount of heat losses associated with the transmission of hot water / steam.

The paper presents the results of calculation of the energy effect of the modernization of a $2.5 \mathrm{~km}$ section of the heat transmission installation, which is part of the heating system that supplies heat for the purpose of heating and utility hot water preparation. After more than four decades of use, the condition of some of the main ducts was rated as very poor (Fig. 1). That is due to the following reasons:

- significant corrosion of pipes,

- significant deterioration of thermal insulation, including its local absence;

- mechanical damage to the construction of heating ducts, and others.

The effect of this are excessive heat losses resulting from the installation wear condition, which is affected by a long-term use, including extremely unfavorable conditions (moisture influence), as well as the method and quality of its assembly. This is accompanied by significant losses of the network water, resulting from the leaks caused by progressive corrosion and perforation of pipes. The condition and excessive heat losses have been the reason for carrying out a comprehensive modernization of the part of installation, consisting in its replacement with new pipelines, made in accordance with the applicable insulation standards, along the new route.

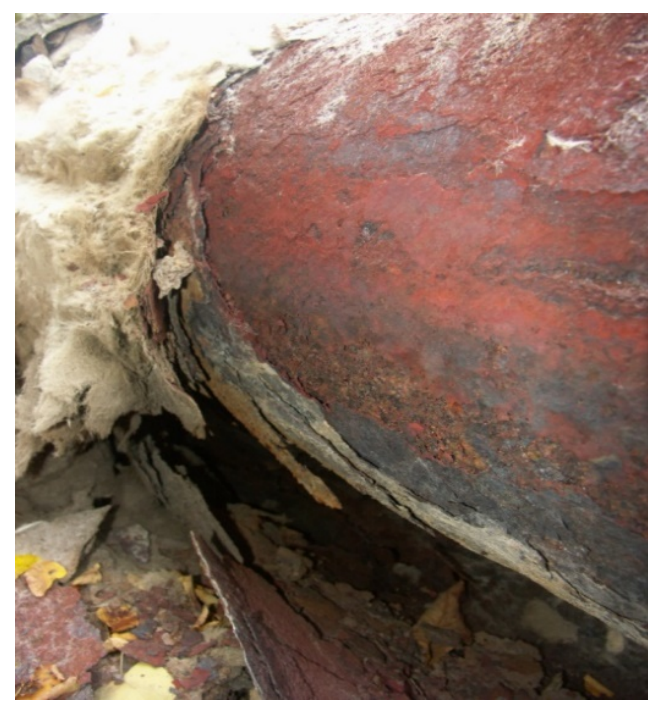

Fig. 1. Technical condition of the transmission installation.

\section{The object of analysis}

The heat transmission line, which was scheduled for modernization, connecting the heat source with the

\footnotetext{
${ }^{*}$ Corresponding author: aleksander.stachel@zut.edu.pl
} 
number of recipients, was built in the 1970s. In suburban areas it is made as a surface installation, while within the city borders it has been laid underground. Each of the constituting pipelines, i.e. both the supply and return pipelines, are arranged in separate ducts located next to each other and made of prefabricated elements (Fig. 2).

The pipelines were made of steel pipes of nominal diameter Dn-350 and Dn-300, respectively. The pipes were thermally insulated with glass wool mats, protected with asbestos-cement coating. The insulation thickness (glass wool) was $80 \mathrm{~mm}$ (Dn-350 pipeline) and $40 \mathrm{~mm}$ (Dn-300), respectively. The pipelines were placed on a variable depth in relation to the surface, while the average depth measured to the horizontal axis of the pipes was $1.1 \mathrm{~m}$. An integral part of the line was a set of fifteen heating chambers intercepted by both pipelines [1].

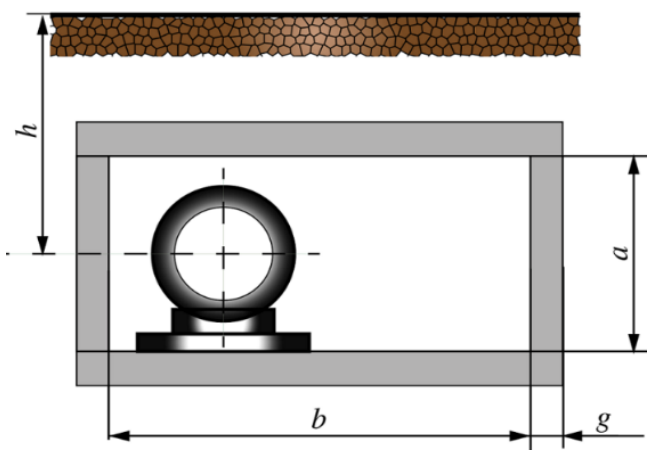

Fig. 2. Construction of the heating pipeline in the ducts.

The new heat distribution line was made in the preinsulated pipe technology, in accordance with the contemporary standards [2]. The heating line, designed for operation at $125 / 70^{\circ} \mathrm{C}$ and operating pressure of 1.6 $\mathrm{MPa}$, forms pipes with a nominal diameter of Dn350. In contrast to the existing one, it is laid directly in the ground, i.e. without a dedicated duct. It is complemented by three underground heating chambers.

\section{Assessment of energy effects of modernization}

In the considered case, a measurable effect of modernization should be the reduction of heat losses in the newly constructed heat transmission line, in relation to heat losses in the installation previously operated. Therefore, the absolute energy effect of modernization can be determined from the relation:

$$
\Delta Q=Q_{S I}-Q_{S M}[\mathrm{GJ} / \mathrm{a}]
$$

where:

$Q_{S I} \quad$ - heat losses in the existing heat transmission line (before modernization), GJ/a,

$Q_{S M}$ - heat losses in the modernized heat transmission line, GJ/a.

The relative energy effect, defined as the ratio of the absolute effect to the extent of heat losses in the installation before modernization, is defined by the formula:

$$
\varepsilon_{\text {em }}=\frac{\Delta Q}{Q_{S I}} \cdot 100 \%
$$

The distribution network supplies heat for central heating (during the heating season) and utility hot water preparation (throughout a year). Thus, the total heat losses include losses during the heating season $Q_{s g}$ and off-season $Q_{s l}$ :

$$
Q_{s}=Q_{s g}+Q_{s l}[\mathrm{GJ} / \mathrm{a}]
$$

Heat loss through overall heat transfer in a pipeline of a certain length and within a specified period of time, can be calculated from the expression:

$$
Q_{s i}=8.64 \cdot 10^{-5} q_{s} L_{i} \tau_{s}[\mathrm{GJ} / \text { season }]
$$

where:

$q_{s}$ - average unit heat losses from the pipeline in the specified period, $\mathrm{W} / \mathrm{m}$,

$L_{i}$ - length of considered length of the pipeline, m,

$\tau_{s}$ - time of duration of a specified period of heat supply, number of days,

where the average unit heat losses are referred to the supply and return pipelines, respectively.

\section{Methodology of calculation of heat losses in pipelines}

Determination of the total heat losses from pipelines requires estimation of the unit heat losses for the heating season and off-season, where the problem is to choose the method of their evaluation. Individual heat losses can be determined using the basic relations and general principles of heat transfer available in the literature $[3,4,5,6]$. The method allows for direct consideration of changes in the thermal conductivity coefficient and insulation thickness as well as the network water temperature. Another way to estimate the unit heat losses is the calculation method proposed by NFOŚiGW, developed for the needs of the Operational Program Infrastructure and Environment [7]. In this method, the unit losses are determined taking into account the so-called factor of losses and the index of deterioration of insulation as a result of the aging process resulting from the long-term use. The influence of thermal conductivity and insulation thickness is taken into account indirectly.

\subsection{Calculations of heat losses from pipelines in the no-pass channel}

The linear unit heat losses of a single pipeline in the intransitive channel can be determined using the relationship: 


$$
q_{1}=\frac{t_{1}-t_{k}}{R_{1}}[\mathrm{~W} / \mathrm{m}]
$$

where air temperature inside the channel is given by:

$$
t_{k}=\frac{\frac{t_{1}}{R_{1}}+\frac{t_{g}}{R_{k}+R_{g}}}{\frac{1}{R_{1}}+\frac{1}{R_{k}+R_{g}}}\left[{ }^{\circ} \mathrm{C}\right],
$$

where:

$t_{1} \quad$ - water temperature in the pipeline, ${ }^{\circ} \mathrm{C}$,

$R_{1}$ - unit thermal resistance of the pipeline, defined as:

$$
R_{1}=R_{\alpha 1}+R_{r}+\sum R_{i}+R_{\alpha 2} \quad[\mathrm{~m} \cdot \mathrm{K} / \mathrm{W}]
$$

where the particular quantities denote the following resistances:

$R_{\alpha 1} \quad$ - convective resistance from the fluid to the inner pipeline wall,

$R_{\alpha 2}$ - convective resistance from the external pipeline wall (insulation) to the surroundings (channel),

$R_{r} \quad$ - heat conduction through the pipeline wall,

$\sum R_{i}$ - heat conduction through subsequent layers of insulations (sum of resistances).

The thermal resistance of the channel wall and thermal resistance of the soil $\left(R_{k}+R_{g}\right)$ occurring in the equation (6), as well as resistance in the relation (7) were calculated in accordance with the methodology given in [6].

\subsection{Calculations of heat losses in pipelines in district heating chambers}

In contrast to the main pipelines placed in separate channels, the pipelines in the heating chambers (supply and return ones) are arranged next to each other. The individual heat losses of each of them can be determined from the formulas:

$$
q_{1}=\frac{t_{1}-t_{k}}{R_{1}}, \quad q_{2}=\frac{t_{2}-t_{k}}{R_{2}} \quad[\mathrm{~W} / \mathrm{m}]
$$

where air temperature inside the channel is determined by:

$$
t_{k}=\frac{\frac{t_{1}}{R_{1}}+\frac{t_{2}}{R_{2}}+\frac{t_{g}}{R_{k}+R_{g}}}{\frac{1}{R_{1}}+\frac{1}{R_{2}}+\frac{1}{R_{k}+R_{g}}}\left[{ }^{\circ} \mathrm{C}\right],
$$

where:

$t_{1}, t_{2}$ - water temperature in considered pipelines,

$R_{1}, R_{2}$ - unit thermal resistances of pipelines, defined by relations (7),
$R_{k}, R_{g}$ - thermal resistance of the channel wall and resistance of the soil, evaluated according to methodology given in [6].

\subsection{An algorithm for calculating the heat losses of pipelines laid in the ground}

The unit linear heat losses of the pipeline laid directly in the ground are defined by the formulas:

- supply pipeline:

$$
q_{1}=\frac{\left(t_{1}-t_{g}\right) R_{2}-\left(t_{2}-t_{g}\right) R_{o}}{R_{1} R_{2}-R_{o}^{2}}[\mathrm{~W} / \mathrm{m}]
$$

- return pipeline:

$$
q_{2}=\frac{\left(t_{2}-t_{g}\right) R_{1}-\left(t_{1}-t_{g}\right) R_{o}}{R_{1} R_{2}-R_{o}^{2}}[\mathrm{~W} / \mathrm{m}]
$$

where the thermal resistances of both pipelines $\left(R_{1}, R_{2}\right)$ are described by the relation:

$$
R_{1}=R_{\alpha 1}+R_{r}+\sum R_{i}+R_{g}[\mathrm{~m} \cdot \mathrm{K} / \mathrm{W}]
$$

where:

$R_{g}$ - thermal resistance of soil:

$$
R_{g}=\frac{1}{2 \pi \lambda_{g}} \ln \frac{4 h}{d_{i j}}
$$

$R_{o}$ - additional thermal resistance for two pipes laid side by side (Fig. 3):

$$
R_{o}=\frac{1}{2 \pi \lambda_{g}} \ln \sqrt{1+\left(\frac{2 h}{b}\right)^{2}} \quad[\mathrm{~m} \cdot \mathrm{K} / \mathrm{W}],
$$

$\lambda_{g}$ - solid thermal conductivity, $\mathrm{W} /(\mathrm{m} \cdot \mathrm{K})$,

$h$ - depth of location of the pipeline measured from the surface to the horizontal pipe axis, $m$,

$b$ - depth of location of the pipeline measured from the surface to the horizontal pipe axis, $\mathrm{m}$,

$d_{i j} \quad$ - outside diameter of the pipeline insulation, $\mathrm{m}$.

\subsection{An algorithm of calculation of unit heat losses in line with the methodology by NFOŚiGW}

The methodology is based on a different method of determining heat losses should be in contrast to that given above. The unit heat loss of both pipelines (supply and return) are determined by the formulas [7]:

- for the heating season:

$$
q_{s}=u \cdot\left(t_{1 s r}+t_{2 s r}-2 \cdot t_{s}\right)[\mathrm{W} / \mathrm{m}]
$$

- outside the heating season: 


$$
q_{l}=u \cdot\left(110-2 \cdot t_{s}\right) \quad[\mathrm{W} / \mathrm{m}]
$$

where:

$u$ - heat loss coefficient characterizing the pipeline, $\mathrm{W} /(\mathrm{m} \cdot \mathrm{K})$ :

$$
u=a \cdot u_{o}
$$

a - an indicator that takes into account the deterioration of insulation due to ageing, depending on the pipeline's operating time,

$u_{o}$ - base coefficient of heat loss in the determined on the basis of the nominal diameter pipeline, $\mathrm{W} /(\mathrm{m} \cdot \mathrm{K})$.

$t_{z-s r 1}, t_{z-s r 2}$ - average outside temperature in the heating period and outside it, ${ }^{\circ} \mathrm{C}$,

$t_{1 s r}, t_{2 s r}$ - average temperature of water in the supply and return pipelines during the heating season, determined on the basis of the regulatory chart, at the assumption that $t_{z}=t_{z-s r 1}$, where $t_{Z}$ - is outer (surroundings) temperature.

$t_{s}$ - temperature outside the pipeline (for a pipeline located in the ground $t_{s}=8^{\circ} \mathrm{C}$, for the one placed in the duct it depends on the nominal network temperature [8],

In calculations of newly constructed pipelines, the heat loss coefficient $\mathrm{u}$ is based on the information taken from the pre-insulated pipe manufacturer.

\section{Results of calculations of heat losses}

The energy effect of modernization of the part of heat transmission line was determined in two ways. The first one was based on the detailed calculations made on the basis of actual operational data of the existing and modernized installations; the second one used the methodology proposed by the National Fund for Environmental Protection and Water Management (Polish acronym NFOŚiGW).

\subsection{Heat losses in the existing heat transmit- ssion line (to be modernized)}

Calculations of heat losses concern the supply and return pipelines being $2462 \mathrm{~m}$ long each, arranged in two independent channels. They also include pipelines with a total length of $57.5 \mathrm{~m}$ (each), passing through a set of 15 heating chambers located along the line. The analysis did not take into account the thermal interaction of channels.

The calculations were carried out in two ways, i.e. in the simplified and exact manner. The first one was based on average values of the calculation period, assuming the temperature of water in pipelines in relation to the average monthly external temperatures, taking into account the number of hours of their occurrence in a given month. In the second one - on real values, determined for each month when outside temperatures were found in the range $-6^{\circ} \mathrm{C}$ to $+12^{\circ} \mathrm{C}$ (with a $1 \mathrm{~K}$ interval) and on this basis, determining the water temperature.

The necessary for calculating the water temperature in the supply and return pipelines were made available by the operator of the heat source, where it should be noted that they are variable and dependent, among others from weather conditions. Outdoor temperatures, including monthly averages, were adopted for the nearest meteorological station, according to MIiB [8]. The soil temperature was determined for the average pipeline installation depth of $1.0 \mathrm{~m}$. It was assumed that the ground is moderately moist.

The calculations were carried out according to the algorithms given in sections $4.1-4.3$. The individual components of thermal resistance were determined based on the designs available in the subject literature. The calculations took into account the design insulation thicknesses of the pipelines, correspondingly reduced due to the operating time and unfavorable working conditions.

- Heat losses in pipelines arranged in intransitive channels.

The calculations concerned the supply pipeline and the return pipeline with the dimensions given in the Table 1. In the analysis the following thermal conduction coefficients were assumed: for pipes $\lambda_{r}=51 \mathrm{~W} /(\mathrm{m} \cdot \mathrm{K})$, for insulation $\lambda_{r}=51 \mathrm{~W} /(\mathrm{m} \cdot \mathrm{K})$ and for heat channel $\lambda_{\text {kan }}=1.7 \mathrm{~W} /(\mathrm{m} \cdot \mathrm{K})$. The design insulation thickness was reduced by $10 \mathrm{~mm}$.

\section{- Heat losses in pipelines arranged in chambers.}

In calculating of heat losses in pipelines passing through the heating chambers, the relationships given in section 4.2 and the data contained in the work [6,7] were used.

Table 1. Dimensions of pipelines and heating ducts of the

\begin{tabular}{|c|c|c|c|c|}
\hline Quantity & \multicolumn{2}{|c|}{$\begin{array}{l}\text { Symbol / } \\
\text { dimension }\end{array}$} & $\begin{array}{l}\text { Supply } \\
\text { pipeline } \\
\text { Dn } 350\end{array}$ & $\begin{array}{l}\text { Return } \\
\text { pipeline } \\
\text { Dn } 300\end{array}$ \\
\hline $\begin{array}{l}\text { Pipe internal } \\
\text { diameter }\end{array}$ & $D_{1}$ & \multirow{4}{*}[\mathrm{mm}]{} & 340 & 308 \\
\hline $\begin{array}{l}\text { Pipe external } \\
\text { diameter }\end{array}$ & $D_{2}$ & & 356 & 324 \\
\hline $\begin{array}{l}\text { Insulation external } \\
\text { diameter }\end{array}$ & $D_{3}$ & & 515 & 404 \\
\hline $\begin{array}{l}\text { Shield external } \\
\text { diameter }\end{array}$ & $D_{4}$ & & 545 & 434 \\
\hline Channel height & $a$ & \multirow{4}{*}[\mathrm{m}]{} & 0.81 & 0.72 \\
\hline Channel breadth & $b$ & & 0.82 & 1.42 \\
\hline $\begin{array}{l}\text { Channel wall } \\
\text { thickness }\end{array}$ & $g$ & & 0.12 & 0.126 \\
\hline Depth of location & $h$ & & 1.0 & 1.0 \\
\hline
\end{tabular}
existing transmission main (to be exchanged).

The results of calculations of heat losses of pipelines situated in the ducts and in district heating chambers are given in Table 2. 
Table 2. Results of calculations of heat losses in the supply and return pipelines arranged in channels and heating chambers obtained by a simplified and exact method [GJ/a].

\begin{tabular}{|l|c|c|}
\hline \multicolumn{1}{|c|}{ Pipeline } & $\begin{array}{c}\text { Exact } \\
\text { method }\end{array}$ & $\begin{array}{c}\text { Simplified } \\
\text { method }\end{array}$ \\
\hline Supply pipeline & 4315.2 & 4269.0 \\
\hline Return pipeline & 2179.9 & 2161.5 \\
\hline $\begin{array}{l}\text { Heating chambers: } \\
\text { supply and return pipelines }\end{array}$ & 187.5 & 162.2 \\
\hline
\end{tabular}

\subsection{Heat losses in the modernized (new) network}

The calculations concerned pipelines made in preinsulated pipe technology, placed directly in the ground and forming a new transmission main with a length of $2470.4 \mathrm{~m}$, as well as other pipelines with a total length of $16.8 \mathrm{~m}$ each, passing through three heat chambers. The pipelines were made of pre-insulated pipes with a nominal diameter of Dn-350 and differ between themselves in the thickness of insulation (supplying pipeline: $d_{i} / d_{z} / d_{w}=344.4 / 355.6 / 520 \mathrm{~mm}$; return pipeline: $\left.d_{i} / d_{z} / d_{w}=344.4 / 355.6 / 500 \mathrm{~mm}\right)$. The given values refer to the inner and outer diameter of the pipes and the outer diameter of the insulation, respectively. The pipelines are located at a distance of $0.75 \mathrm{~m}$ from each other and located at a depth of $1.2 \mathrm{~m}$ below the surface (Fig.3).

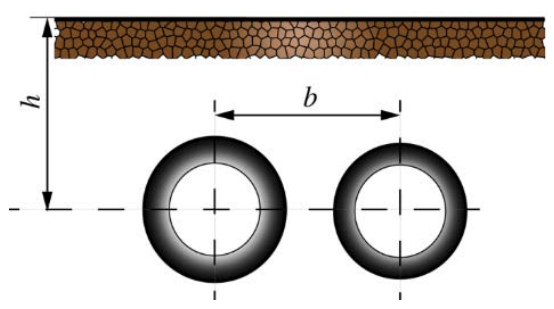

Fig. 3. Location of pipelines pre-insulated in the ground.

Calculations of heat losses in both main pipelines, as well as in those passing through the chambers, were made according to the algorithm given in sections 4.2 and 4.3. The results of calculations are presented in the Table 3.

Table 3. The results of calculation of heat losses in pipelines (supply and return ones) laid in the ground and in 3 heating chambers $[\mathrm{GJ} / \mathrm{a}]$.

\begin{tabular}{|l|c|c|}
\hline \multicolumn{1}{|c|}{ Pipeline } & $\begin{array}{c}\text { Exact } \\
\text { method }\end{array}$ & $\begin{array}{c}\text { Simplified } \\
\text { method }\end{array}$ \\
\hline - from pre-insulated pipes & 3609.8 & 3574.3 \\
\hline - in 3 heating chambers & 29.0 & 25.0 \\
\hline
\end{tabular}

\section{Calculation of the energy effect of modernization}

Calculation of heat losses in the existing distribution main and in the newly created one made it possible to determine the energy effect of modernization, using both the exact and simplified methods.
In addition, the energy effect was determined based on the NFOŚiGW methodology [2], using the algorithm given in section 4.4. Apart from the necessary for the calculation data previously specified, based on meteorological data, the duration of the heating season was adopted as $\tau_{\mathrm{s}}=242$ days (Szczecin) and the average external temperature was determined $t_{z-s r 1}=6.0^{\circ} \mathrm{C}$ ) based on the available long-term data [8]. The results of calculations are given in the Table 4 .

Table 4. Energy effect (reduction of heat losses) due to modernization of heating main.

\begin{tabular}{|c|c|c|c|}
\hline \multirow{2}{*}{$\begin{array}{c}\text { Annual } \\
\text { savings }\end{array}$} & \multicolumn{3}{|c|}{ Method } \\
\cline { 2 - 4 } & simplified & exact & $\begin{array}{c}\text { according to } \\
\text { NFOŚiGW }\end{array}$ \\
\hline$\Delta Q[\mathrm{GJ} / \mathrm{a}]$ & 2993.4 & 3043.8 & 7218.4 \\
\hline$\varepsilon_{m}[\%]$ & 45.4 & 45.5 & 63.4 \\
\hline
\end{tabular}

Assumptions for the calculation of the heating network before modernization are as follows. Thermal network operation time exceeds 30 years. Adopted on this basis insulation deterioration ratio is $a=1.85$. On the other hand, the base heat loss coefficient in the pipeline, determined for the nominal diameters, is equal to $u_{o}=1.0299 \mathrm{~W} /(\mathrm{m} \cdot \mathrm{K})$ [6]. Average water temperatures in the supply and return pipelines, determined on the basis of the calculation methodology, are: $t_{1 s r}=79^{\circ} \mathrm{C}$; $t_{2 s r}=48^{\circ} \mathrm{C}$. The air temperature in the channels, being a function of the maximum design temperature of the supply and return fluid and the nominal pipeline diameter, is equal to $t_{s}=23^{\circ} \mathrm{C}$.

Assumptions for the calculation of the heating network after modernization are as follows. The newly made installation from pre-insulated pipes with a diameter Dn-350 is laid directly in the ground. According to the calculation methodology, the soil temperature at the pipe depth is set at $t_{s}=8^{\circ} \mathrm{C}$. The heat loss coefficient of the new pre-insulated pipes is $u=0.509 \mathrm{~W} /(\mathrm{m} \cdot \mathrm{K})$ [9].

Calculated on the basis of relations (15) and (16) unit heat losses of pipelines in the heating season $q_{s}$ and off-season $q_{l}$ allowed to calculate the total annual heat losses, both for the old installation (before modernization) and a new installation. The calculation results are given below (Table 5).

Table 5. The results of calculations of heat losses in the installation before and after modernization, obtained using the WFOŚiGW method [GJ/a].

\begin{tabular}{|c|c|}
\hline $\begin{array}{c}\text { Before } \\
\text { modernization }\end{array}$ & $\begin{array}{c}\text { After } \\
\text { modernization }\end{array}$ \\
\hline 11392.8 & 4174.4 \\
\hline
\end{tabular}

\section{Conclusions}

The above results of calculations enable to formulate a number of conclusions important from the point of view of engineering practice. 
Calculation of the energy effects of modernization was related to the determination of the overall heat losses, both in the case of old and newly built installations. The energy effect was determined in three different ways. It should be noted that the analysis did not take into account heat losses associated with leakages of heating fluid.

The results of calculation are shown graphically in the Figures $4-7$.

In the Fig. 4 presented are unit heat losses recorded in the annual cycle for subsequent calculation periods, determined for the supply and return pipelines of the installation before and after its modernization. The chart shows that the unit losses in the installation after modernization are much lower (almost twice) than before modernization. It also follows that the unit losses depend on the outside temperature and on the parameters (temperature) of the heating fluid (water). The lowest values were obtained for the summer season (July, August), whereas the highest for the winter period.

In the Fig. 5 are presented average unit heat losses from pipelines: supply and return installation before modernization (channel) and after modernization (preinsulated), related to the annual cycle of work.

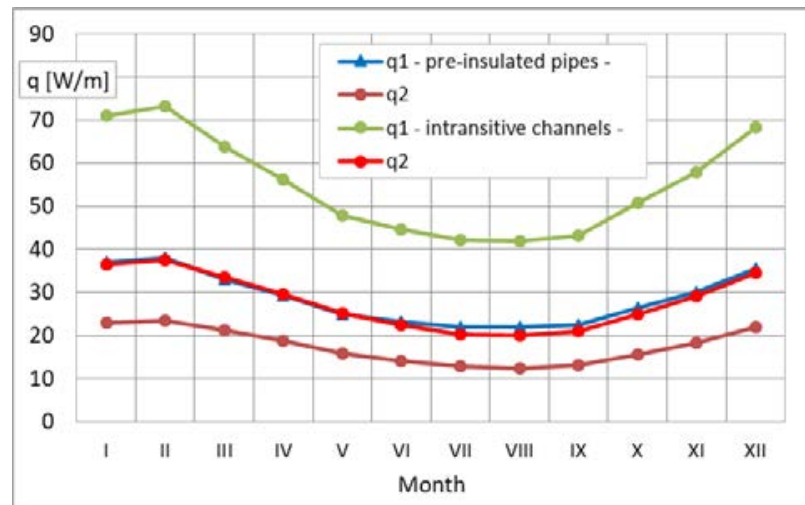

Fig. 4. Unit heat losses from the supply and return pipelines before and after the modernization of the installation, related to subsequent calculation periods (months).

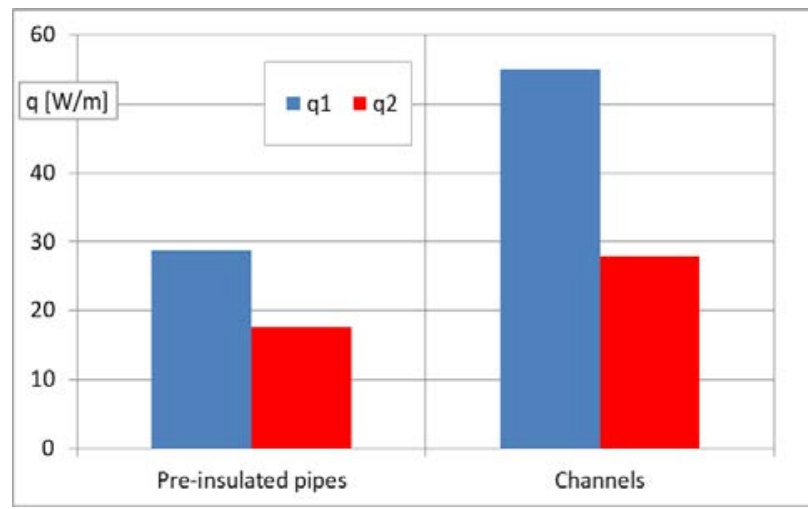

Fig. 5. Unit heat losses recorded in the annual cycle, determined for the supply and return pipelines of the installation before and after its modernization.

Analysis and evaluation of obtained results indicates that there are significant differences in the extent of determined energy effect, depending on the applied calculation method (Fig.6). Similar results were obtained for the methods relying on real data. The results of calculations carried out using the exact and simplified manner are close to each other and do not show significant differences. The effects calculated by these methods differ by 0.1 percentage points. It can therefore be assumed that both methods are equivalent, where the simplified method being easier to use.

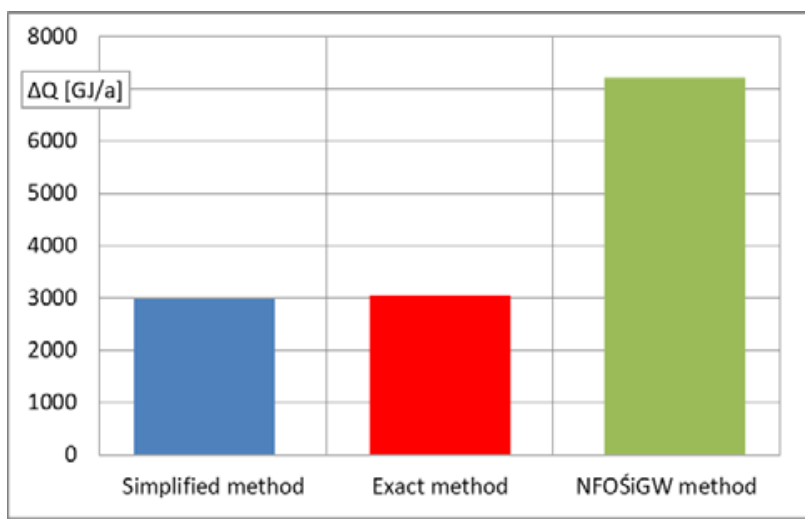

Fig. 6. Energy effect of the modernization of the installation determined by basic (exact and simplified) methods and the NFOŚGW method.

In turn, the heat losses calculated using the NFOŚiGW method exceed the losses determined by the basic calculation method, both by simplified and exact approaches. The relative energy effect of modernization is also larger, based on this method. In the case at hand, the difference reaches several (eighteen) percentage points. This also applies to the calculation of total heat losses, as shown in Fig. 7.

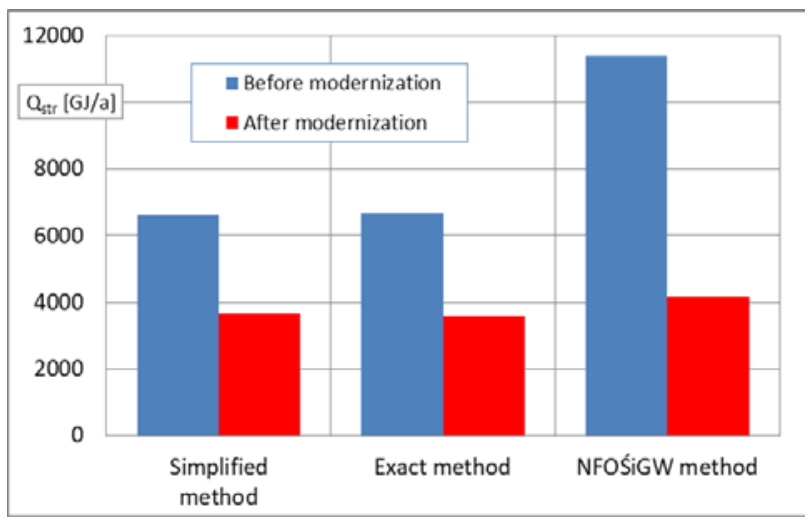

Fig. 7. Total annual heat loss from the supply and return pipelines before and after the modernization of the installation.

It stems from the presented analysis that this is probably the effect of several factors, among others:

- adopted high value of the insulation deterioration factor (multiplier: $\alpha=1.85$ ),

- adopted, and not calculated, value of the heat loss coefficient,

- assumptions of some pipeline operational parameters.

The advantages of the method include simple formulas for calculation of heat losses, both for new as well as the networks operated for many years, which enables quick calculation. The disadvantage is a lack of a direct reference to the condition and thickness of the 
insulation, which parameters are decisive when determining the unit size of heat losses. It follows that for the sake of accurate analysis the formulas that take into account a number of parameters, such as thickness and condition of insulation, type of heat network, changes in the soil temperature as a function of outside temperature, etc. should rather be used for more accurate calculations.

Regardless of these remarks and irrespective of the size of the calculated energy effect (smaller - larger), the conducted analysis shows that replacing the existing heating main with a new installation, made according to modern technologies and in accordance with the applicable requirements, brings measurable benefits in the form of significant reduction of heat losses.

\section{References}

1. Internal unreleased materials of DHE (Department of Heat Engineering, West Pomeranian University of Technology, Szczecin, 2016).

2. Polish Standard PN-EN 13941:2003, Design and construction of heating networks from a system of pre-insulated composite pipes (PKN, Warszawa 2009).

3. W. Kamler, Heating (PWN, Warszawa, 1976).
4. T. Hobler, Heat exchange and heat exchangers (WNT, Warszawa, 1986).

5. J. Madejski, Theory of heat exchange (Szczecin, 1998).

6. A. Tarnowska-Tierling, Thermal equipment for the power plant; part. 1. Pipelines (Publishing House of University of Technology, Szczecin, 1981).

7. Methodology for estimating the reduction of heat losses (pipes). POIŚ 2007-13: Section 9.2 Effective energy distribution. (NFOŚiGW, Warszawa 2010).

8. http://mib.gov.pl/ (access: 21.03.2016).

9. Finpol-Rohr, Designer's guide (Warszawa, 2006).

\section{Nomenclature}

$\begin{array}{lll}d, D & \text { diameter of the pipe } & \mathrm{m} \\ \Delta & \text { difference } & - \\ \varepsilon & \text { efficiency of modernization } & \% \\ \lambda & \text { thermal conductivity } & \mathrm{m} \cdot \mathrm{K} / \mathrm{W} \\ q & \text { unit heat loss } & \mathrm{W} / \mathrm{m} \\ Q & \text { heat } & \mathrm{kJ} \\ L & \text { length of the pipe } & \mathrm{m} \\ t & \text { temperature } & { }^{\circ} \mathrm{C} \\ R & \text { thermal resistance } & \mathrm{m} \cdot \mathrm{K} / \mathrm{W} \\ \tau & \text { period of time } & \mathrm{days}\end{array}$

